\title{
Impact of Repeated Prevention of Mother to Child Transmission of HIV (PMTCT) Services on Vertical Transmission of HIV Infection in Southwest Nigeria
}

\author{
Article by Abayomi Joseph Afe ${ }^{1}$, Opeyemi Akano ${ }^{1}$, Adeniyi Aderoba ${ }^{2}$, Oluwafemi R. \\ Olubanke $^{2}$, Adebara I.O ${ }^{3}$, Olufunke Bolaji ${ }^{3}$, Michael O. Gbala ${ }^{4}$, Akinkumi B.F ${ }^{4}$, Pius \\ Idowu Ade-Ojo ${ }^{5}$, Ogundare E. Olatunde ${ }^{6}$ \\ 1 Community Medicine Department, Equitable Health Access Initiative, Lagos Nigeria \\ 2 Obstetrics \& Gynaecology Dept, Mother and Child Hospital Akure, Ondo, Nigeria \\ 2 Paediatrics Dept, Mother and Child Hospital, Akure, Ondo, Nigeria \\ 3 Obstetrics \& Gynaecology Dept, Federal Teaching Hospital, Ido Ekiti, Ekiti, Nigeria \\ 3 Paediatrics Dept, Federal Teaching Hospital, Ido Ekiti, Ekiti, Nigeria \\ 4 Obstetrics \& Gynaecology Dept, Mother and Child Hospital Ondo, Ondo, Nigeria \\ 4 Paediatrics Dept, Mother and Child Hospital Ondo, Ondo, Nigeria \\ 5 Obstetrics \& Gynaecology Dept, Ekiti State University Teaching Hospital, Ado Ekiti, \\ Ekiti, Nigeria. \\ 6 Paediatrics Dept, Ekiti State University Teaching Hospital, Ado Ekiti, Ekiti, Nigeria. \\ E-mail:abayomiafe@yahoo.com
}

\begin{abstract}
Background: In Nigeria about 50,000 children are infected with HIV annually, mostly through mother to child transmission, thus making her the greatest contributor (30\%) to the global paediatric HIV burden. Since the inception of the PMTCT programme in Nigeria in 2001, the number of HIV+ pregnant women that had accessed the service was more than 200,000. Some accessing the service more than one time during different pregnancies.

Objectives: The study was conducted primarily to determine, if there was any, the impact of maternal exposure to repeated PMTCT care on the rate of mother to child transmission of HIV infection. Other secondary objectives included calculating the proportion of PMTCT clients who are accessing the PMTCT service for the first time, the 2nd, 3rd or 4th time

Methods: This was a retrospective case-control multicenter study. PMTCT clients who have had repeated PMTCT services form the case while the control group consisted of first-timers PMTCT clients.

Results: The control group consists of 387 HIV positive nursing mothers who were assessing the PMTCT service for the first time while the case group consisted 116 who were repeated users of the PMTCT service. Of the repeated PMTCT clients (case group), 95\% ( $n=110)$ were accessing the PMTCT service for the $2^{\text {nd }}$ time while $5 \%(n=6)$ were third time users of the PMTCT service. None had used the service for more than $3^{\text {rd }}$ time. HIV vertical transmission rate was $0 \%$ among babies of mothers who were having repeated PMTCT service(case group) while only $1.4 \%$ babies whose mothers were receiving PMTCT service for the first time(control) were vertically infected.

Conclusion: Though the vertical transmission of HIV was slightly higher among babies whose mothers were exposed to the PMTCT service for the first time. The difference in the transmission rates between the two groups was not statistically significant $P>0.05, X^{2}=1.309$, $d f=1)$ and there was no statistical association between the number of vertically HIV infected infants and the number of time the mother was exposed to PMTCT services.
\end{abstract}

Keywords: HIV (human immunodeficiency virus), Prevention of Mother To child Transmission of HIV (PMTCT), ARV (antiretroviral drugs), PCR (polymerase chain reaction), Seroconversion, HAART. 
South American Journal of Public Health

Volume 4, Issue 2, 2016

\section{Introduction}

Worldwide there were about 36million people living with HIV infection as at 2014. About70 \% (25million) of these lives in Sub-Saharan Africa. $(1,2)$. Nigeria has the second highest burden of HIV infection with about 3.4 million of her population living with the HIV infection (3). Though $80 \%$ of HIV infections occurs by heterosexual intercourse, mother to child transmission of HIV infection (MTCT) accounts for another 10\% of HIV transmissions. MTCT or vertical transmission is responsible for $90 \%$ of all paediaric HIV infection (4). In 2014, 3.3 million children were living with HIV and 220,000 of these were newly infected worldwide (2). $91 \%$ of these (3million) live in Sub-Saharan Africa (1). Nigeria also accounts for $30 \%$ of the global burden of vertical transmission of HIV infection, making her the greatest contributor to the global paediatric HIV burden (5). In 2014 alone; Nigeria had 58,000 (51,000-66,000) new paediatric HIV infections (11). Prevention of mother to child transmission (PMTCT) is a comprehensive package of interventions that includes HIV testing and counseling (HTC), infant feeding counseling, family planning counseling and services, antiretroviral (ARV) and cotrimoxazole prophylaxis for mother-infant pairs, early infant diagnosis (EID), screening of the mother for cervical cancer, and eligibility assessment of the mother for lifelong antiretroviral therapy (ART) (7-9). These proven interventions are so effective that they can reduce the rate of vertical transmission to as low as $2 \%$ from the highest rate of $45 \%$ obtained in scenarios where there was no intervention (12, 17-19). ARV regimen in combined form of highly active antiretroviral therapy (HAART) has been found to be effective in reducing vertical transmission among Nigerian women (20). However, the Nigerian national coverage for each of these services ranges from less than 5\% for early infant diagnosis( EID ) at two months to about 30\% for maternal ARV prophylaxis(9). A situation where at least $90 \%$ of HIV-infected women would have access to comprehensive PMTCT services including ARV prophylaxis during pregnancy and the breastfeeding period would give rise to what is known as eMTCT,(Elimination of Mother to Child Transmission of HIV infection) where vertical transmission of HIV infection no longer constitute a public health problem as achieved in Cuba recently(6). Though there has been a steady increase in the proportion of HIV positive pregnant women in Nigeria who received ARVs for PMTCT to $27 \%$ of the $244,000 \mathrm{HIV}$-infected pregnant women in 2013 and by $9.5 \%$ from 2013 to 2014(10). Mother to child HIV transmission (MTCT) rate in Nigeria is still high at $28 \%$ as at 2014 (13). Apart from all the known risk factors associated with HIV vertical transmission, which are responsible for the high rate of vertical transmission, other unknown and yet to be studied risk factors may also contribute to this high rate of transmission; one of which may be the number of times an HIV positive woman is accessing the PMTCT services. Examples of some already known risk factors for mother to child transmission of HIV include high maternal viral load, advanced HIV disease, immune deficiency, HIV infection acquired during pregnancy or breastfeeding, co-infection with sexually transmitted infections, malaria, vaginal delivery in absence of ARV coverage, prolonged rupture of membranes, prolonged labour, fetal prematurity, multiple delivery, mixed feeding, complicated breastfeeding, and lack of antiretroviral drugs use in the mother and or the baby. Since the inception of the PMTCT service in Nigeria in 2001, many HIV positive pregnant women have accessed this service not once but at several times with different number of pregnancies.

According to the integrated Nigerian national guideline for HIV prevention, treatment and care 2014 (4), all HIV positive pregnant women should continue ARV prophylaxis until one week after complete cessation of breastfeeding. This is also known as Option B approach. Thereafter the mother-baby pair should be referred to ART clinic for proper evaluation for comprehensive HIV treatment and care for mother and child. Women that meet treatment eligibility criteria $(\mathrm{CD} 4+$ cell count $<500)$ should then be enrolled for ART while those not eligible should be enrolled for pre-ART care. The ARV drugs is then either stop in the women after breastfeeding cessation for those who are not eligible for ART(CD4+cell count $>500)$ or continue after breastfeeding cessation as ART for the mother with CD4+cell count $<500$. The same protocol of ARV treatment or prophylaxis is repeated when the women present in subsequent pregnancies. The probability of an HIV positive pregnant women returning for 
antenatal care in subsequent pregnancies is moderately high as some studies have shown an increase in fertility of HIV positive women as they commence antiretroviral therapy to almost the same level as HIV negative women (14-16). The objective of this research therefore is to study the impact if any the number of PMTCT services a woman has had on her chance of transmitting the HIV infection to her unborn baby. The authors are not aware of similar studies and therefore hope to provide a new body of knowledge and lay foundation for future works.

\subsection{Objectives}

1) Determine the proportion of PMTCT clients who are accessing PMTCT for the first time

2) Determine the proportion and number of PMTCT clients who are accessing PMTCT service for the $2 \mathrm{nd}$, 3rd or 4 th time.

3) Determine the incidence of vertical HIV transmission among the two groups outlined above.

4) Determine the statistical difference in the incidences of vertical transmissions between the two groups.

5) Determine statistical association between the number of PMTCT services a woman had and her rate of vertical HIV transmission

\subsection{Research question}

Do babies of HIV positive mothers with repeated exposure to PMTCT services have lower rate of vertical HIV infection transmission?

\section{Materials and methods}

2.1.1 Study Type. Cross sectional questionnaire-based.

2.1.2 Study Design: A retrospective case-control. The cases comprised of PMTCT clients who have had PMTCT services $2^{\text {nd }}, 3^{\text {rd }}$, or $4^{\text {th }}$ time. The control group is made up of first-timers PMTCT clients.

2.1.3 Study Location: Four public health facilities in southwest Nigeria (Multicenter)

1) Mother and Child Hospital Ondo, Ondo

2) Mother and Child Hospital Akure, Ondo

3) Ekiti State University Teaching Hospital, Ado Ekiti, Ekiti

4) Federal Teaching Hospital Ido, Ekiti

2.1.4 Study Duration: Jan. to Dec.2015

2.1.5 Study Population: PMTCT clients

2.2. Sample Size Determination: The sample size was calculated using raosoft statistical package online (http://www.raosoft.com/samplesize.html) with the following assumptions; confidence limit $=95 \%$, margin error $=5 \%$, population size $=20,000$ and response distribution $=50 \%$. This gives sample size of 377 (approx.380) and 10\% mark up to 400 .

2.1.2 Sampling Method: Convenient sampling

Inclusion Criteria for the study participants

1) Registered PMTCT clients between Jan.2010 and Dec.2014

2) Must have delivered at least one live HIV exposed infant

2) Available DNA PCR results of the exposed babies

4) Available medical records of mother and baby pair

2.1.3 Data Collection: Questionnaires were designed for this study, and this was tested for validity and reliability using expert opinion and pre-testing with potential study participants before they were finally administered by the interviewers. After the interview, they were checked for completeness before entry into an access data-base. Only those with complete information were used. 
South American Journal of Public Health

Volume 4, Issue 2, 2016

\subsection{Result}

Table 1: Features of Respondents

\begin{tabular}{|c|c|c|c|}
\hline \multicolumn{2}{|l|}{ Age } & Frequency & Percentage Frequency \\
\hline \multicolumn{4}{|l|}{$\mathrm{S} / \mathrm{N}$} \\
\hline 1 & $20-30$ & 192 & 38.2 \\
\hline 2 & $31-40$ & 292 & 58.1 \\
\hline 3 & $41-50$ & 18 & 3.6 \\
\hline 4 & $>50$ & 1 & 0.2 \\
\hline Total & Total(n) & $\mathrm{n}=503$ & 100 \\
\hline \multicolumn{2}{|c|}{ Educational Level } & Frequency & Percentage Frequency \\
\hline \multicolumn{4}{|c|}{ 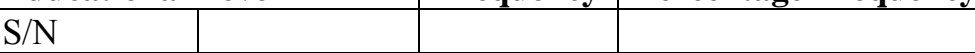 } \\
\hline 1 & None & 69 & 13.7 \\
\hline 2 & Primary & 109 & 21.7 \\
\hline 3 & Secondary & 204 & 40.6 \\
\hline \multirow[t]{2}{*}{4} & Tertiary & 121 & 24.1 \\
\hline & Total(n) & $\mathrm{n}=503$ & 100 \\
\hline \multicolumn{2}{|l|}{ Religion } & Frequency & Percentage Frequency \\
\hline \multicolumn{4}{|l|}{$\mathrm{S} / \mathrm{N}$} \\
\hline 1 & Christian & 462 & 91.8 \\
\hline \multirow[t]{2}{*}{2} & Muslim & 41 & 8.2 \\
\hline & Total(n) & $\mathrm{n}=503$ & 100 \\
\hline Occupation & & Frequency & Percentage Frequency \\
\hline 1 & Artesian & 45 & 8.9 \\
\hline 2 & Civil servant & 50 & 9.9 \\
\hline 3 & Professional & 76 & 15.1 \\
\hline 4 & Trading & 258 & 51.3 \\
\hline \multirow[t]{2}{*}{5} & Unemployed & 74 & 14.7 \\
\hline & Total $(\mathrm{n})$ & $\mathrm{n}=503$ & 100 \\
\hline \multicolumn{2}{|c|}{$\begin{array}{l}\text { HIV diagnosis prior to } \\
\text { the last pregnancy }\end{array}$} & Frequency & Percentage Frequency \\
\hline 1 & No & 357 & 71 \\
\hline \multirow[t]{2}{*}{2} & Yes & 146 & 29 \\
\hline & Total & 503 & 100 \\
\hline \multicolumn{2}{|c|}{$\begin{array}{l}\text { Outcome of Last } \\
\text { Pregnancy }\end{array}$} & Frequency & Percentage Frequency \\
\hline 1 & Miscarriage & 1 & 0.2 \\
\hline 2 & $\begin{array}{l}\text { caesarean } \\
\text { Section }\end{array}$ & 36 & 7.2 \\
\hline \multirow[t]{2}{*}{3} & SVD & 466 & 92.6 \\
\hline & Total(n) & $\mathrm{n}=503$ & 100 \\
\hline
\end{tabular}

Table 2: HIV Vertical Transmission Risk Factors among Respondents

\begin{tabular}{|l|l|l|l|}
\hline \multicolumn{2}{|l|}{ Recent CD4 count(cells/mm ${ }^{3}$ ) } & Frequency & Percentage Frequency \\
\hline \multicolumn{2}{|l|}{} & & \\
\hline 1 & $<200$ & 63 & 12.5 \\
\hline 2 & $200-350$ & 28 & 5.6 \\
\hline 3 & $>350-500$ & 90 & 17.9 \\
\hline
\end{tabular}




\begin{tabular}{|c|c|c|c|}
\hline 4 & $>500$ & 322 & 64 \\
\hline & Total(n) & $\mathrm{n}=503$ & 100 \\
\hline & Maternal ARV Use & Frequency & Percentage Frequency \\
\hline 1 & ARV prophylaxis & 13 & 2.6 \\
\hline 2 & ARV Therapeutic & 490 & 97.4 \\
\hline & Total & 503 & 100 \\
\hline & hal Age at last & Frequency & Percentage Frequency \\
\hline 1 & Pre-term $(<37 \mathrm{wks})$ & 23 & 4.4 \\
\hline 2 & $\operatorname{Term}(\geq 37 \mathrm{wks})$ & 479 & 89.3 \\
\hline & Total(n) & $\mathrm{n}=502$ & 93.6 \\
\hline & of last delivery & Frequency & Percentage Frequency \\
\hline & Home & 9 & 1.8 \\
\hline & Hospital & 487 & 96.8 \\
\hline & TBA & 6 & 1.2 \\
\hline & Total(n) & $\mathrm{n}=502$ & 99.8 \\
\hline & $\begin{array}{l}\text { RV prophylaxis for } \\
\text { sed baby }\end{array}$ & Frequency & Percentage Frequency \\
\hline & No & 15 & 3 \\
\hline & Yes & 487 & 97 \\
\hline & Total(n) & $\mathrm{n}=502$ & 100 \\
\hline & $\begin{array}{l}\text { Infant feeding of } \\
\text { exposed baby }\end{array}$ & Frequency & Percentage Frequency \\
\hline & Breastfeeding & 490 & 97.6 \\
\hline & Replacement feeding & 12 & 2.4 \\
\hline & Total(n) & $\mathrm{n}=502$ & 100.0 \\
\hline
\end{tabular}

Table 3: No of Exposure to PMTCT Services

\begin{tabular}{|c|c|c|c|}
\hline \multicolumn{2}{|l|}{ No of times of accessing PMTCT service } & Frequency & Percentage \\
\hline Control Group & First Timers PMTCT & 387 & 76.9 \\
\hline Case Group & $\begin{array}{l}\text { Repeated PMTCT } \\
\text { Users }\end{array}$ & 116 & 23.1 \\
\hline & Total(n) & $\mathrm{n}=503$ & 100.0 \\
\hline \multicolumn{2}{|l|}{ No of times of accessing PMTCT service } & Frequency & Percentage \\
\hline \multirow{4}{*}{$\begin{array}{l}\text { 1st time PMTCT User(Control Group) } \\
\text { Repeated PMTCT Users(Case Group) }\end{array}$} & First Timers PMTCT & 387 & 76.9 \\
\hline & $\begin{array}{l}\text { Second Timers } \\
\text { PMTCT }\end{array}$ & 110 & 21.9 \\
\hline & Third Timers PMTCT & 6 & 1.2 \\
\hline & Total(n) & $\mathrm{n}=503$ & 100 \\
\hline
\end{tabular}

Table 4: HIV DNA PCR Results of Exposed Babies

\begin{tabular}{|c|c|c|c|}
\hline \multicolumn{2}{|c|}{$\begin{array}{l}\text { HIV DNA PCR result of last exposed } \\
\text { baby }\end{array}$} & \multirow[t]{2}{*}{ Frequency } & \multirow[t]{2}{*}{ Percentage Frequency } \\
\hline $\mathrm{S} / \mathrm{N}$ & & & \\
\hline & PCR result Positive & 4 & 0.8 \\
\hline & PCR result Negative & 492 & 98.0 \\
\hline & Neonatal death before PCR & 6 & 1.2 \\
\hline & Total(n) & $\mathrm{n}=502$ & 100.0 \\
\hline
\end{tabular}


South American Journal of Public Health

Volume 4, Issue 2, 2016

\begin{tabular}{|c|c|c|c|}
\hline \multicolumn{2}{|c|}{$\begin{array}{l}\text { HIV DNA PCR result of the Previous } \\
\text { First Exposed baby }\end{array}$} & \multirow[t]{2}{*}{ Frequency } & \multirow[t]{2}{*}{ Percentage Frequency } \\
\hline $\mathrm{S} / \mathrm{N}$ & & & \\
\hline & Negative PCR & 102 & 88.7 \\
\hline & Positive PCR & 4 & 3.5 \\
\hline & Neonatal death before PCR & 10 & 8.7 \\
\hline & $\operatorname{Total}(\mathrm{n})$ & $\mathrm{n}=116$ & 100.9 \\
\hline
\end{tabular}

Table 5: Comparing First-timer and Repeated PMTCT Clients

\begin{tabular}{|c|c|c|c|}
\hline $\begin{array}{l}\text { PCR Result of Last } \\
\text { Exposed baby }\end{array}$ & $\begin{array}{l}\text { Repeated PMTCT } \\
\text { delivery(Case) }\end{array}$ & $\begin{array}{l}\text { 1st timer PMTCT } \\
\text { delivery(Control) }\end{array}$ & Chi Square Test \\
\hline Positive PCR result & $0(0 \%)$ & $4(1.04 \%)$ & \multirow{3}{*}{$\begin{array}{l}X^{2}=1.309, \mathrm{df}=1 \\
P \text { value }>0.05\end{array}$} \\
\hline Negative PCR & $116(100 \%)$ & $376(99.47 \%)$ & \\
\hline $\begin{array}{l}\text { Neonatal death before } \\
\text { PCR }\end{array}$ & 0 & 6 & \\
\hline Total & $\mathrm{n}=116$ & $\mathrm{n}=386$ & \\
\hline $\begin{array}{l}\text { Maternal ARV } \\
\text { Prophylaxis }\end{array}$ & $\begin{array}{l}\text { Repeated PMTCT } \\
\text { delivery }\end{array}$ & $\begin{array}{l}\text { 1st timer PMTCT } \\
\text { delivery }\end{array}$ & Chi Square Test \\
\hline Yes & $116(100 \%)$ & $341(88.11 \%)$ & \multirow{2}{*}{$\begin{array}{l}\mathrm{X}^{2}=15.2, \mathrm{df}=1 \mathrm{P} \\
\text { value }<0.05\end{array}$} \\
\hline No & $0(0 \%)$ & $46(11.89 \%)$ & \\
\hline Total & $116(100 \%)$ & $387(100 \%)$ & \\
\hline $\begin{array}{l}\text { Mode Delivery of } \\
\text { Last Pregnancy }\end{array}$ & $\begin{array}{l}\text { Repeated PMTCT } \\
\text { delivery }\end{array}$ & $\begin{array}{l}\text { 1st timer PMTCT } \\
\text { delivery }\end{array}$ & Chi Square Test \\
\hline SVD & $102(87.9 \%)$ & $364(93.7 \%)$ & $\mathrm{P}$ value $>0.05$ \\
\hline Caesarean section & $14(12.1 \%)$ & $22(6.0 \%)$ & \\
\hline Abortion & $0(0 \%)$ & $1(0.3 \%)$ & \\
\hline Total & $116(100 \%)$ & $365(100 \%)$ & \\
\hline Delivery at term & $\begin{array}{l}\text { Repeated PMTCT } \\
\text { delivery }\end{array}$ & $\begin{array}{l}\text { 1st timer PMTCT } \\
\text { delivery }\end{array}$ & Chi Square Test \\
\hline Yes & $113(97.41 \%)$ & $366(94.82 \%)$ & \multirow{3}{*}{$\begin{array}{l}X^{2}=1.37, d f=1 \\
P \text { value }>0.05\end{array}$} \\
\hline No & $3(2.59 \%)$ & $20(5.18 \%)$ & \\
\hline Total & $n=116$ & $\mathrm{n}=386$ & \\
\hline $\begin{array}{l}\text { Mode of Infant } \\
\text { Feeding In Last } \\
\text { Delivery }\end{array}$ & $\begin{array}{l}\text { Repeated PMTCT } \\
\text { delivery }\end{array}$ & $\begin{array}{l}\text { 1st timer PMTCT } \\
\text { delivery }\end{array}$ & Chi Square Test \\
\hline Breastfeeding & $116(100 \%)$ & $374(96.89 \%)$ & \multirow{2}{*}{$\begin{array}{l}\mathrm{X}^{2}=4.41, \mathrm{df}=1 \\
\mathrm{P} \text { value }<0.05\end{array}$} \\
\hline Replacement feeding & $0(0 \%)$ & $12(3.11 \%)$ & \\
\hline Total & $116(100 \%)$ & $386(100 \%)$ & \\
\hline $\begin{array}{c}\text { Infant ARV } \\
\text { Prophylaxis }\end{array}$ & $\begin{array}{l}\text { Repeated PMTCT } \\
\text { delivery }\end{array}$ & $\begin{array}{l}\text { 1st timer PMTCT } \\
\text { delivery }\end{array}$ & Chi Square Test \\
\hline Yes & $116(100 \%)$ & $376(97.41 \%)$ & \multirow{2}{*}{$\begin{array}{l}X^{2}=3.1, d f=1 \\
P \text { value }>0.05\end{array}$} \\
\hline No & $0(0 \%)$ & $10(2.59 \%)$ & \\
\hline Total & $\mathrm{n}=116$ & $\mathrm{n}=386$ & \\
\hline
\end{tabular}

3.1 Report: A total of 503 HIV positive nursing women were interviewed using interviewer administered questionnaires. About $58 \%$ of them were in the age bracket $31-40 \mathrm{yrs}$ followed by $20-30 \mathrm{yrs}$ age bracket which accounted for $38 \%$. About $41 \%$ of them had secondary school 
education followed by $24 \%$ with tertiary education and $22 \%$ had primary or elementary school education, $14 \%$ had no formal education. Up to $51 \%$ were traders, $15 \%$ were professionals, $10 \%$ civil servants, $9 \%$ were artisans and $15 \%$ were unemployed. About $71 \%$ did not know their HIV status before the last index pregnancy while $29 \%$ claimed they were aware of their HIV status before the last index pregnancy. Almost 93\% delivered their babies via spontaneous vaginal delivery while $7 \%$ had caesarean delivery. Only one had a miscarriage (Table 1).

According to table 2 , up to $64 \%$ had a recent CD4 count of above 500 cell $/ \mathrm{mm}^{3}, 18 \%$ between $>350-500 \mathrm{cell} / \mathrm{mm}^{3}, 5.6 \%$ between $200-350$ cells $/ \mathrm{mm}^{3}$ and $12.5 \%$ below 200 cells $/ \mathrm{mm}^{3}$. They were all on ARV, though $97 \%$ on therapeutics and $3 \%$ on prophylaxis. Nearly $89 \%$ delivered at term gestation while $4 \%$ delivered pre-term. Up to $97 \%$ delivered at the hospitals, $2 \%$ delivered at home and $1 \%$ delivered with the traditional birth attendants (TBA). There were 502 live births with only one miscarriage. Of the 502 HIV exposed babies delivered, there were 6 neonatal death leaving 496 alive at 6 weeks for early infant diagnosis (EID) using HIV DNA PCR test (8). About $97 \%$ of the babies had ARV prophylaxis while 3\% did not have. Almost $98 \%$ of the babies were breastfed while $2 \%$ had replacement feeding. DNA PCR result of $98 \%$ babies was HIV negative while $1 \%$ had positive HIV DNA PCR result (Table 4). Of the 503\% HIV positive women interviewed about $387(77 \%)$ were first time users of the PMTCT service, $110(22 \%)$ were second time users and 6(1\%) were third users (Table 3). The 387 first timer users constitute the Control group while the 110 repeated users form the Case group. Comparing these two groups showed that $100 \%$ of women in the case group had maternal ARV prophylaxis while $88 \%$ of those in the control group took ARV. Up to $97 \%$ of women in the case group delivered at term compared with $94 \%$ of those in the control group. Only one woman in the control group (First timers) had miscarriage, none in the case group had abortion. For mode of delivery, 94\% had normal vaginal delivery and $6 \%$ had caesarean delivery in the control group while in the case group $88 \%$ had spontaneous vaginal delivery and $12 \%$ had caesarean delivery. Virtually all $(100 \%)$ babies of mothers in the case group were breastfed and had ARV prophylaxis while in the control group $97 \%$ babies were breastfed and $97 \%$ had ARV prophylaxis. All the babies $(116 ; 100 \%)$ in the case group had negative HIV DNA PCR result while $99 \%(376)$ of those in the control group had negative HIV DNA PCR results. Only 1\%(4) babies in the control group had positive HIV DNA PCR result (Table 5).

\subsection{Discussions}

A total of 503 HIV positive nursing women who are enrolled in the PMTCT care at the study sites were selected for this study. The control group consists of 387 HIV positive nursing mothers who were assessing the PMTCT service for the first time while the case group consists 116 who were repeated users of the PMTCT service. Of the repeated PMTCT clients (case group), majority $(110 ; 95 \%$ ) were accessing the PMTCT service for the 2 nd time while very few (6; 5\%) were third time users of the PMTCT service, meaning PMTCT clients are more likely to come back for antenatal care in their subsequent pregnancies if they register in the previous ones. (Table 3). The modal age for all the participants was 31-40yrs age bracket, which falls within the reproductive age group of $19-45 \mathrm{yrs}$. About $40 \%$ had secondary or college level of education and $24 \%$ had tertiary level of education and $13 \%$ were illiterates. A reflection of the illiteracy level in the general population. Most $(>80 \%)$ were employed while $15 \%$ were unemployed, though majority through self-employment. Of the 503 subjects about357 (71\%) were newly diagnosed during their antenatal care (ANC) while the other 146(29\%) were previously known HIV positive clients before their ANC registration. This underscores the importance of HIV screening in ANC as a means of diagnosing most HIV infection in pregnant women. With respect to the outcome of the last index pregnancy, virtually all $(93 \%)$ had spontaneous vaginal delivery of live infants, $7 \%$ had caesarean delivery of live neonates and only one had miscarriage, supporting the fact that most HIV positive pregnant would prefer vaginal delivery and this is safe especially when they are on ARV (Table1).

Most (64\%) had a recent CD4 count of above 500cells $/ \mathrm{mm} 3$, which is within the normal range of CD4 count even among the HIV negative population and it's an indication of good health 
status among the clients. They all had triple antiretroviral drugs either for prophylaxis $(3 \%)$ or therapeutic (97\%) based on whether their baseline CD4 count was above or less than 500 cells $/ \mathrm{mm} 3$ respectively according to the Nigerian national guideline. About $89 \%$ (479 women) delivered at term defined as 37 th completed gestational week while $4 \%$ (23 women) had pre-term deliveries. This pre-term rate is less than the $10 \%$ pre-term rate WHO estimates for West Africa in 2005(24). About 487(97\%) of the 502 study women who had viable pregnancies delivered in hospitals, $9(2 \%)$ delivered at home and 6(1\%) delivered with traditional birth attendants(TBA). Though the fractions of those who delivered outside the hospital setting was small, these places are potential areas where PMTCT services can be scale-up for universal health coverage. Though most babies, 487(97\%), had Nevirapine prophylaxis yet about $15(3 \%)$ were not given Nevirapine prohylaxis, thus increasing their chance of HIV infection from the mothers. Reasons for this include the neonatal death, babies born at home and at the TBAs who failed to present in the hospital for Nevirapine prescription. About $98 \%(490)$ of the babies were breastfed while $2 \%(12)$ had replacement with breast milk substitutes. This is a reflection of the high prevalence of breastfeeding in the Nigerian setting.

With respect to the HIV DNA PCR results of the exposed babies, of the 502 exposed babies delivered 4 had positive HIV DNA PCR results, while 492 had negative result and 6 who were dead before the PCR test could not do the test. This gives an HIV sero-positivity rate of about $1 \%(0.8 \%)$ among the exposed babies. This could also mean an HIV vertical transmission rate of $1 \%$, assuming other routes of passing HIV infection to the infants are eliminated (Table 4).

For women who had experienced the PMTCT services more than once (repeated PMTCT users or case), 4 out of their 106 FIRST HIV exposed babies were HIV infected as confirmed by the HIV DNA PCR positive results, giving a vertical transmission rate of $3.5 \%$. But in their LAST index deliveries none of the babies of women in the same repeated PMTCT or case group(n=116) were HIV DNA PCR positive while 4 of the babies of women who were passing though the PMTCT programme for the first time(Control group, $n=386$ ) had positive HIV DNA PCR result. This gives a vertical transmission rate of $0 \%$ for the case group and $1.4 \%$ for the control group respectively. This difference in the transmission rates between the two groups was not statistically significant $(\mathrm{P}>0.05, \mathrm{X} 2=1.309)$ and there was no association between number of times women used the PMTCT services and the HIV status of their babies.

However, women who were repeated PMTCT services users(case group) were more likely to use $\operatorname{ARV}(100 \%$ vs $88 \%, \mathrm{p}<0.05)$ and more likely to breastfeed $(100 \%$ vs $97 \%, \mathrm{p}<0.05)$ when compared with women accessing the service for the first time in the control group. There was also some association between maternal ARV use, breastfeeding an infant and the number of times an HIV positive mother used the PMTCT service, with women in the repeated PMTCT or case group more likely to use ARV and breastfeed than their counterparts who were experiencing the PMTCT services for the first time. There was no significant difference in the mode of delivery, gestational age at delivery and use of infant ARV prophylaxis between the case and control groups.

\subsection{Conclusion}

With the vertical transmission rate of $0 \%$ for the case group and $1.4 \%$ for the control group respectively, there seems to be slightly higher HIV vertical transmission rate among women who were experiencing the PMTCT services for the first time. However the difference in the transmission rates between the two groups was not statistically significant $\left(\mathrm{P}>0.05, \mathrm{X}^{2}=1.309\right)$ and there was no statistical association between vertical transmission rate and the number of times an HIV positive mother was accessing the PMTCT service. However, women who were repeated PMTCT services users (case group) were more likely to use ARV and more likely to breastfeed than women accessing the service for the first time in the control group. There was also no significant difference between women in both groups in terms of mode of delivery, gestational age at delivery and use of infant ARV prophylaxis 


\subsection{Ethical consideration}

Ethical approval number ERC/2015/03/24/188 for the study was obtained from the IRB committee of Federal Teaching Hospital, Ido-ekiti. Individual consent was obtained from the study participants.

\section{Acknowledgement}

We like to acknowledge the following

1) IHVN ACTIONPlus-Up project

2) Equitable Health Access Initiative, ACTIONPlus-Up project

3) HIV Management teams at study facilities

\section{References}

[1]. A.S. Sagay, et al. Vertical transmission of HIV-1 infection in northern Nigeria. : AIDS 2006 - XVI International AIDS Conference: Abstract no. TUPE0345

[2] A review of HIV transmission through breastfeeding. Geneva: UNAIDS and WHO; 1998.

[3] Burgos-Soto J et al. Intimate partner sexual and physical violence among women in Togo, West Africa: prevalence, associated factors, and the specific role of HIV infection. Global Health Action. 2014; 7. doi: 10.3402/gha.v7.23456

[4] DITRAME STUDY GROUP. 6 month efficacy, tolerance and acceptability of a short regime of oral zidovudine to reduce vertical transmission of HIV in breastfed children in coted Ivoire and Burkina Faso: a double -blind placebo-controlled metacentre trial. Lancet, 1999, 353(9155):786-792.

[5] Fitzpatrick, Fidelma, et al. "Use of a fourth generation HIV assay for routine screening-The first years' experience." Journal of Infection 53.6 (2006): 415-416.

[6] Global AIDS Response Country Progress Report, Nigeria GARPR 2012

[7] Global Aids Response Country Progress Report, Nigeria GARPR 2015, National Agency for the Control of AIDS (NACA), Abuja, Nigeria

[8] Homsy $\mathrm{J}$ et al. Reproductive intentions and outcomes among women on antiretroviral therapy in rural Uganda: a prospective cohort study. PloS ONE. 2009; 4(1). doi: 10.1371/journal. pone.0004149

[9] Myer L et al. Impact of antiretroviral therapy on incidence of pregnancy among HIV-infected women in Sub- Saharan Africa: a cohort study. PLoS Medicine. 2010; 7.2: 194.

[10] Nigerian Integrated National Guidelines For HIV Prevention, Treatment And Care 2014

[11] Nigeria National Guidelines on Prevention of Mother-To-Child Transmission (PMTCT) of HIV, 2010

[12] Nigerian National guideline for HIV Counselling and Testing 2012 pg 35.

[13] Nigerian National Operational Plan for the Elimination of Mother to Child Transmission (eMTCT) of HIV in Nigeria 2015-2016, Federal Ministry of Health, Abuja, Nigeria.

[14] PETRA STUDY TEAM. Efficacy of three short-course regimens of zidovudine and lamivudine in preventing early and late transmission of HIV-1 from mother to child in Tanzania, South Africa, and Uganda(Petral study): a randomised, double-blind, placebo-controlled trial. Lancet, 2002, 359(9313):1178-1186

[15] Tonwe-Gold et al. Highly active antiretroviral therapy for the prevention of perinatal HIV transmission in Africa: mother-child-transmission HIV plus, Abidjan, Cote d'Ivoire, 2003-2004. $12^{\text {th }}$ Conference on Retroviruses and Opportunistic Infections, Boston, MA US, 22-25 Feb. 2005 (Abstract 785).

[16] The worldwide incidence of preterm birth: a systematic review of maternal mortality and morbidity http://www.who.int/bulletin/volumes/88/1/08-062554-table-T3.html

[17] UNAIDS 2014 report

[18] UNAIDS 2014 estimates

[19] West and Central Africa Regional Stocktaking Meeting on the Global Plan for the Elimination of Mother-to-Child Transmission of HIV and Keeping Mothers Alive by 2015: The Last 600 Days: Challenges, Opportunities and the Way Forward.

[20] WHO validates elimination of mother-to-child transmission of HIV and syphilis in Cuba Http://www.who.int/mediacentre/news/releases/2015/mtct-hiv-cuba/en/?

[21] 2015 Progress report on the Global Plan UNAIDS / JC 2774/1/E 
South American Journal of Public Health

Volume 4, Issue 2, 2016

\section{Author Profile}

\section{Dr Abayomi Joseph Afe, MBBS, MPH, Ph.D(Cand.)TAU}

Author's profile: Dr Aabayomi J.Afe is a public health physician with specialization in Reproductive health and Infectious diseases. He has a postgraduate training in obstetrics and gyanecology and over 10years experience in managing HIV cases both as a clinician and public health programme manager on the USG PEPFAR HIV project. He is a passionate researcher with publications in peer-reviewed journals and an editorial board member of other scientific journals. He is a principal investigator on two research grants and a co-investigator on two other grants. 